\title{
Assessment of Growing Pain and Its Risk Factors in School Children
}

\author{
Mujammel Haque*, Kamrul Laila, Mohammed Mahbubul Islam, Mohammad Imnul Islam, \\ Manik Kumar Talukder, Shahana Akhter Rahman
}

Department of Paediatrics, Bangabandhu Sheikh Mujib Medical University, Shahbag, Dhaka, Bangladesh

Email address:

mujammeljewel@gmail.com (M. Haque),drlaila28@yahoo.com (K. Laila),mahbub25SOMC@gmail.com (M. M. Islam), imon27@gmail.com (M. I. Islam), talukder.manik@gmail.com (M. K. Talukder), shahana2pd@yahoo.com (S. A. Rahman)

${ }^{*}$ Corresponding author

\section{To cite this article:}

Mujammel Haque, Kamrul Laila, Mohammed Mahbubul Islam, Mohammad Imnul Islam, Manik Kumar Talukder, Shahana Akhter Rahman. Assessment of Growing Pain and Its Risk Factors in School Children. American Journal of Clinical and Experimental Medicine. Vol. 4, No. 5, 2016, pp. 151-155. doi: 10.11648/j.ajcem.20160405.17

Received: August 31, 2016; Accepted: September 14, 2016; Published: October 17, 2016

\begin{abstract}
Background: Limb pain in children is a major diagnostic challenge. In majority of cases limb pain are due to growing pain (GP), which is the most common form of episodic childhood musculoskeletal pain. Some standard criteria are being used for diagnosis of GP. Objective: This study was undertaken to identify the frequency of growing pain and to determine its presentation and risk factors in school children. Methodology: This cross sectional study was conducted from January 2014 to December 2014 among school children aged 6-12 years in four Kindergarten schools at Bhairab Thana in Kishoregonj District. Standard criteria given by Peterson (1986) were used in this study for diagnosis of GP. Pretested questionnaires in Bangla were distributed among the children of Class One to Class Five by purposive sampling. After completions by parents or caregiver, questionnaires were collected from the schools and children with limb pain were selected for further history and clinical examination. Age and sex matched healthy children were selected as controls for comparison of risk factors. Results: Among 540 distributed questionnaires 404 (74.8\%) responded. Among responders 95 (23.5\%) had limb pain of which $78(19.3 \%)$ were diagnosed as GP ( 40 were male and 38 were female). Highest number of cases was found in 8+ year age group. Site of pain was calf muscle (69.2\%) in the majority. Timing of pain was at night in $82.05 \%$ cases. In $66.6 \%$ of cases pain was improved with massage. GP hampered activities like sleep in $26.9 \%$, sports in $21.7 \%$ and schooling in $8.9 \%$. GP was associated with headache in $12.8 \%$ and abdominal pain in $6.4 \%$ cases. Obesity, overweight, over activity and family history of GP were found significantly higher among GP cases than controls. Conclusion: Growing pain was found to be the most common cause of limb pain. Typical presentation of GP and multiple risk factors like obesity, over activity and family history were identified in this study.
\end{abstract}

Keywords: Limb Pain, Growing Pain, Risk Factors

\section{Introduction}

Limb pain is common in children. "The common causes of chronic or recurrent limb pain in children include accidental injuries, joint hyper mobility, viral infections and reactive arthritis [1]". Growing pain (GP) is the most common form of episodic childhood musculoskeletal pain. "Medical science is still unable to fully explain the exact causes of the discomfort experienced by up to one third of all children at some time during early childhood [2]".
"The proposed causes of GP according to Yosef Uziel and Philip J Hashkes are (De Inocencio, 2004): low pain tolerance, over use, low bone strength density, mechanical strains due to flat foot with mild outward turning of back of foot, blood perfusion change, family environment, stress and psychological disposition [2,3]".

Correct diagnosis of GP requires a thorough history and physical examination. Currently, the diagnosis is based only on typical clinical symptoms and exclusion criteria. When patients have typical clinical characteristics there is no need to do any unnecessary laboratory investigation or imaging 
tests. However, if the symptoms are atypical, the diagnosis of GP should not be assumed without evaluating other causes.

So, there is a need for assessment of GP and community impact of growing pain in school children. Thereby increasing the awareness among the parents and doctors society regarding growing pain.

\section{Materials and Methods}

A cross sectional study was done for assessment of frequency of GP. Subsequently a case control study was done for evaluation of risk factors. The study was conducted in four kindergarten schools at Bhairab Thana in Kishoregonj District, from January 2014 to December 2014. Ethical clearance was taken from Institutional Review Board (I.R.B.) of BSMMU.

The samples were collected from selected Kindergarten schools by purposive sampling. All the children in the selected Kindergarten schools, aged 6-12 years were included in this study. School children who present at the day of visit were included in the study. Children who had definite joint manifestation (swelling, redness, trauma, reduced joint range, limping), did not give consent and did not complete the questionnaire were excluded from the study.

A questionnaire was developed to identify any children who may have limb pain, whatever may be the duration, severity or timing. Questionnaire contained title of study, school name and address, child's name, age, sex, class, roll, father's name, mother's name, present address, contact number and date of questionnaire fill up. Some questions regarding limb pain in Bengali such as site, duration, persisting of pain in each episode, timing of limb pain, relieving factor, over activity, hampers daily activities and family history of limb pain were included. Questionnaire had few options for probable answer. School Principals / Head Teachers were approached by a letter from the guide to seek permission for distribution of questionnaires among the children of class One to class Five. Children were advised to give these letters to their parents or caregivers who took care of these children whole day and night. After completion of questionnaire by parents, students were requested to return it to his or her class teacher within next three working days. Returned questionnaires were collected from schools and children with limb pain were selected for further history and clinical examination. Parents were interviewed regarding the history of limb pain in the child, followed by clinical examination which included anthropometry (height, weight, BMI), locomotor system examination and other systemic examination.

"Diagnostic criteria of GP given by Peterson (1986) includes: intermittent pains occurring once or twice per week, rarely daily, totally pain free in between the episodes; individual episodes lasting for 30 minutes to 2 hours. Sites are usually in the muscles of calf, sometimes anterior thigh muscles, shins and popliteal fossa and affect both limbs. Time of pain is in the evening or night, and physical examination is normal [4]".
Seventy eight age and sex matched healthy children were selected from same schools as controls for comparison of risk factors. Risk factors such as over activity, obesity and family history were compared among cases and controls.

Height \& weight of healthy control was taken and BMI was calculated. Principal investigator himself talked to the parents of healthy control directly in school ground for information such as activities of the child in hours and family history of limb pain.

Data was expressed as frequency, percentage, range, mean and standard deviation $( \pm \mathrm{SD})$. Mann-Whitney $U$ test and Chi-square test were performed to compare between cases and controls. $p$ values $<0.05$ was accepted as a level of significance.

\section{Results}

Total 540 questionnaires were distributed among students of class one to five. Among 540 students, a total of 404 (74.81\%) students responded, comprising $51.28 \%$ male and $48.72 \%$ female.

Among responders $78(19.3 \%)$ children were found to have GP. Seventeen children (4.2\%) were diagnosed as other than GP (Table 1).

Table 1. Possible causes of limb pain in studied children by history and clinical examination $(n=404)$.

\begin{tabular}{lll}
\hline Variables & Frequency (n) & Percent (\%) \\
\hline $\begin{array}{l}\text { Diagnosis of growing pain } \\
\text { (Among responder) }\end{array}$ & 78 & 19.3 \\
Other than GP & 17 & 4.2 \\
Healthy child & 309 & 76.4 \\
Total & 404 & 100 \\
\hline
\end{tabular}

GP was found in all the age groups. However there was a peak at $8+$ years of age $(29.5 \%)$ followed by $7+$ years (Table 2).

Table 2. Age distribution of children with growing pain $(n=78)$.

\begin{tabular}{lll}
\hline Age in year & Number of children with GP(n) & Percent $(\%)$ \\
\hline $6+$ & 10 & 12.8 \\
$7+$ & 15 & 19.2 \\
$8+$ & 23 & 29.4 \\
$9+$ & 13 & 16.6 \\
$10+$ & 14 & 17.9 \\
$11+$ & 03 & 3.8 \\
\hline
\end{tabular}

Regarding site of GP, most cases had pain over calf muscle $(69.2 \%)$. In some cases pain was found in back of knee and front of thigh. There were overlapped sites in some cases of GP (Table 3). Eighty two percent children with GP experienced pain during night and only $17.9 \%$ had pain during evening. Table 3 shows maximum number of GP cases $(35.9 \%)$ had disease duration of 7-12 months followed by $32.05 \%$ (had duration of 13-24 months). Regarding duration of persistence of pain $41.02 \%$ had $\leq 30$ minutes. In $66.6 \%$ of cases pain improved with massage, pain also improved with medicine and spontaneously. Medicines and massage were simultaneously effective for pain relieving in 
some cases. Medications used were paracetamol, calcium, NSAID and cefixime. More than half of children with growing pain had disturbance of daily activities such as sleep disturbances, sports and schooling problem. GP was associated with headache in $12.8 \%$ and abdominal pain in $6.4 \%$.

Table 3. Characteristics of growing pain $(n=78)$.

\begin{tabular}{|c|c|c|}
\hline \multicolumn{3}{|c|}{ Commonest location of pain } \\
\hline Site of pain & Number (n) & Percent (\%) \\
\hline Calf muscle & 54 & 69.2 \\
\hline Front of thigh & 10 & 12.8 \\
\hline \multicolumn{3}{|l|}{ Timing of Pain } \\
\hline Timing & Number (n) & Percent $(\%)$ \\
\hline Evening & 14 & 17.9 \\
\hline \multicolumn{3}{|c|}{ Total duration of pain } \\
\hline$\leq 6$ month & 12 & 15.3 \\
\hline $7-12$ month & 28 & 35.9 \\
\hline 13-24 month & 25 & 32 \\
\hline$>24$ month & 13 & 16.6 \\
\hline \multicolumn{3}{|c|}{ Duration of persistence of pain } \\
\hline$\leq 30$ minutes & 32 & 41 \\
\hline $31-60$ minutes & 29 & 37.1 \\
\hline \multicolumn{3}{|l|}{ Pain decrease with } \\
\hline Massage & 52 & 66.6 \\
\hline Medicine & 20 & 25.6 \\
\hline Sponteneously & 15 & 19.2 \\
\hline \multicolumn{3}{|c|}{ Hampers activities like } \\
\hline Sleep & 21 & 26.9 \\
\hline Sports & 17 & 21.7 \\
\hline Schooling & 7 & 8.9 \\
\hline \multicolumn{3}{|c|}{ Pain associated with } \\
\hline Headache & 10 & 12.8 \\
\hline Abdominal pain & 5 & 6.4 \\
\hline
\end{tabular}

Table 4 shows the relationship of risk factors among cases and controls. Equal number of cases were overweight (15.4\%) and obese (15.4\%) among cases, where as there was only one obese child and no overweight among control group. Overweight, obesity, over activity and family history were compared between cases and controls. These parameters were significantly higher among cases.

Table 4. Relation of risk factors of growing pain with healthy controls $(n=78+78)$.

\begin{tabular}{llll}
\hline Parameters & Cases with GP $(\mathbf{n}=\mathbf{7 8})$ & Healthy control $(\mathbf{n}=\mathbf{7 8})$ & P value \\
\hline Overweight $\left(85^{\text {th }}-<95^{\text {th }}\right.$ centile $)$ & $12(15.4 \%)$ & 0 & $<0.001^{* * *}$ \\
Obesity $\left(\mathrm{BMI} \geq 95^{\text {th }}\right.$ centile $)$ & $12(15.4 \%)$ & $1(1.2 \%)$ & $7(9 \%)$ \\
Overactivity & $21(26.9 \%)$ & $5(6.4 \%)$ & $<0.01^{* *}$ \\
Family history & $37(47.4 \%)$ & $<0.01^{* *}$ & $<0.001^{* * *}$ \\
\hline
\end{tabular}

\section{Discussion}

The current study was the pioneer study done in the field of Growing Pain among school children in Bangladesh. "Evans et al. (2004) found a 63\% response rate across all regions surveyed in and considered to be good in survey research [5]". Our response rate was $74.81 \%$. "Studies of the prevalence of growing pains have showed a wide range of estimates from 2.6 to $49.4 \%$ [6]". This is mainly due to different and unspecified sample sizes, different age ranges and lack of objective diagnostic criteria adopted in different studies. "A study by Kaspiris and Zafiropoulou reported a prevalence of $24.5 \%$ among 532 children aged $4-12$ years [7]". We found the frequency of growing pain to be $19.3 \%$ in this study.

"Abu-arafeh \& Russel in their study reported that sports and playground injuries were the most common cause of limb pain and the prevalence of recurrent limb pain was $2.6 \%$ [8]". But our study found that most cases of recurrent limb pain were due to GP and only $4.21 \%$ had limb pain due to other causes which included minor sports injuries.

"GP mainly affects children between the ages of 3-12 years. The incidence peaks between the ages of 8 and 12 years [9]". Two third of cases of GP in this study were found in 8-12 years age group.

In our study we found slight male preponderance. This could be due to the fact that numbers of boys were more than girls in the selected schools. Another factor may be social background where male children receive more attention than 
female.

"Children with GP have significantly greater body weight (about 5\% heavier) [2]". In the current study, about one third of GP cases were found to be either overweight or obese whereas in healthy control group only one child was obese and there was no overweight child. "Genetic component may play a role in the pathogenesis of GP [6]". "About half of the children with GP had positive family history of GP and this was significantly higher than control group $(\mathrm{P}<0.001)$ which supports Oster's findings [10]". "Naish and Apley assumed that emotional disturbances are more common in children with GP [1]". In the current study family environment and psychosocial disposition could not be evaluated. "In a eight years longitudinal study of school children the prevalence of headache and abdominal pain among GP cases were $20.6 \%$ and $14.4 \%$ respectively [10]". Our study also found increased susceptibility of these children to other pains and aches such as headache and abdominal pain.

"Two third (69\%) of children in the current study had limb pain in calf muscle which matched with Uzeil (2010) study [11]". In our study, all children had pain mostly at night and at evening $(82.05 \%$ and $17.9 \%$ respectively), which is consistent with Kaspiris \& Zafiropoulou study [7]. "Frequent episodes of GP may have a major impact on the child and his family's daily routine [12]". Our study revealed that GP hampered daily activities like sleep disturbance in $26.9 \%$, sports in $21.7 \%$ and schooling in $8.9 \%$ of cases.

"Hashkes et al. showed that $52 \%$ of children used medication to relieve their pain [13]". In our study 57.6\% children had history of medication use mainly paracetamol $(37.1 \%)$. Some of them had calcium $(15.3 \%)$ and NSAID (3.8\%). Episodes of growing pains are reported on days of increased activity and during the latter part of a day. These observations probably signify that growing pains represent a local overuse syndrome leading to bone fatigue [14]. Over activity was significantly higher in children with GP in comparison with healthy control.

Management of growing pain adopted by parents differs widely. "According to Kaspiris \& Zafiropoulou (2009) most popular treatment appears to be massaging (77.5\%) [7]". In the current study a similar finding was observed where pain was improved with massaging in most of the cases $(66.6 \%)$. In some cases pain improved with medication or spontaneously or in combination with massage $\&$ medicine. "Hypovitaminosis D may have a role in pathogenesis of growing pains [15]". All children with unexplained limb pains without identifiable organic pathology should be tested for vitamin D status. and treated, if necessary.

The findings of this study support that obesity, over activity and positive family history are risk factors of GP in children.

\section{Conclusion}

Growing pain (GP) is a frequent problem in paediatric practice. In this study frequency of GP was found as 19.3\% among school children. From this study age distribution, other characteristics of growing pain and multiple risk factors like overweight, obesity, over activity and family history were identified as risk factors of Growing Pain. Paeditrician should be more cautious to differentiate this benign unexplained limb pain from other chronic musculoskeletal pain.

\section{Limitations}

Sample size was small and taken purposively from four selected schools. Family environment could not be evaluated in this study.

\section{Acknowledgements}

I convey my sincere gratefulness to my honorable teacher, Professor Shahana Akhter Rahman, Chairman, Department of Paediatrics, BSMMU, whose direct supervision; time to time constructive suggestions helped me to complete my research. I am very much grateful to my respected teacher, Dr Mohammad Imnul Islam, Associate Professor, Department of Paediatrics, BSMMU for his affectionate advice starting from title selection till completion of the study.

\section{References}

[1] Naish JM, Apley J. Growing pains: A clinical study of nonarthritic limb pains in children. Arch Dis Child 1951; 26, 134-40.

[2] De Inocencio J. Epidemiology of musculoskeletal pain in primary care. Arch Dis Child 2004; 89 (5), 431-4.

[3] www.betterhealthvic. Gov.au: Growing pain. Better health channel 2010;1-2.

[4] Petersen H. Growing pains. Pediatr Clin North Am 1986; 33, 1365-72.

[5] Evans AM, Scutter SD. Prevalence of "growing pains" in young children. J Pediatr 2004; 145, 255-8.

[6] Evans AM. Growing pains: contemporary knowledge and recommended practice. J Foot Ankle Research 2008; 1, 4.

[7] Kaspiris A, Zafiropoulou C. Growing pains in children: Epidemiological analysis in a Mediterranean population. Joint Bone Spine 2009; 76, 486-90.

[8] Abu-Arafeh I, Russel G. Recurrent limb pain in school Children. Arch Dis Child 1996; 74, 336-9.

[9] Nell DB. Growing pains in Children. The Parentreport. com $2010 ; 05,1-3$.

[10] Oster J, Neilsen A. Growing pains: clinical investigation of a school population. Acta Pediatrica Scandinavica 1972; 61, 329-34.

[11] Uziel Y, Chapnick G, Jaber L, Nemet D, Hashkes PJ. Fiveyear outcome of children with growing pains: Correlation with pain threshold. J Pediatr 2010; 156, 838-40.

[12] Uziel Y, Hashkes PJ. Growing Pains in Children. J Foot Ankle Research 2008; 1, 4-7 
[13] Haskesh PJ, Friedland O, Jaber L, Cohen A, Wolach B, Uziel Y. Decreased pain threshold in children with growing pains. J Rheumatol 2004; 31, 610-3.

[14] Lowe RM, Hashkes PJ. Growing pains: a noninflammatory pain syndrome of early childhood. Nat Clin Pract Rheumatol 2008; 4, 542-9.

[15] Sobia Qamar, Shaheena Akbani, Samina Shamimand, Gulsambar Khan. Vitamin D level in children with growing pains. J Coll Physicians Surg Pak 2011; 21 (5), 284-287.

\section{Biography}

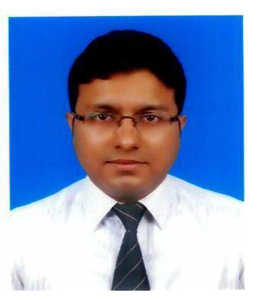

Mujammel Haque, MD Paediatrics. He worked as a Residential Medical Officer, Paediatrics, Jahurul Islam Medical College, Bajitpur, Bangladesh. Currently he has completed his MD in Paediatrics and working as a senior resident in Bangabandhu Sheikh Mujib Medical University, Dhaka, Bangladesh. 